\title{
Comparison of student perception and exam validity, reliability and items difficulty: cross-sectional study.
}

\begin{abstract}
:
Introduction: Student perception of an exam is a reflection of their feelings towards the exam items, while item analysis is a statistical analysis of students' responses to exam items. The study was formulated to compare the student's perception of the results of item analysis. Material and methods: Type of the study is cross-sectional. The study was conducted in the college of medicine, in the duration from January to April 2019. The study uses a structured questionnaire and standardized item analysis of students' exam. Participants are students registered for semester two level year (2018-2019). Exclusion criteria included all students who refused to participate in the study or do not fill the questionnaire.

Result: The response rate of the questionnaire was $88.9 \%$ (40/45). Students considered the exam as easy (70.4\%). The average difficulty index of the exam is acceptable. KR-20 of the exam was 0.906. A significant correlation was reported between student perceptions towards exam difficulty and standard exam difficulty. Discussion: Student perceptions support the evidances of exam vlaitdity. Students can estimate exam difficulty.
\end{abstract}

Keyword: Student perception, Item analysis, Assessment, validity, reiliablity. 


\section{Introduction}

Students' perception of an exam is a reflection of their feelings towards the exam items, while item analysis is a statistical analysis of students' responses on exam items. Whether students' perception or item analysis is agreed or not, they represent different views about exam items.

Students' perception is widely used and recommended in medical education. Data generated from students' perception can provide information about faculty, the achievement of educational objectives, and instructional methods $(1,2)$. Also, it is considered as a reliable and valid indicator of effective teaching (3).

Construct validity denoted as "a unitary concept, requiring multiple lines of evidence, to support the appropriateness, meaningfulness of the specific inferences made from test scores"(4). Thus, the assessment is considered valid if measures what is intended to measure and reflects the educational contents $(5,6)$. The mismatch between the level of the cognitive process in the assessment and the educational task can affect exam validity and reliability $(5,7)$. The mismatch can appear in the form of too many easy or difficult items.

Item analysis is a mathematical analysis of students' responses on an exam to evaluate items quality and consequently improving the assessment. This can be done either by refining the defected or deletion of poorly constructed from the questions bank (8-10). Quality of items is evaluated through a variety of item 
analysis parameters, which include Difficulty Index (DIF) and the index of the internal consistency (KR-20). DIF is defined as the percentage of the examinees who answered the item correctly. It ranges from $0 \%$ to $100 \%$; with a higher value indicating an easy item (11).

Commonly the internal consistency is measured through Cronbach's $\alpha$. (Coefficient alpha) $(8,12,13)$. Coefficient alpha is identical to Kuder-Richardson formula 20 (KR-20) when each item has a single answer (MCQs Type A)(8, 14, 15). There are different ranges and interpretations of item analysis parameters and internal consistency published in the literature $(12,15-20)$ (Table 1).

The college of Medicine, adopts SPICE curriculum. Problem-based learning is the principal educational strategy as well as an instructional method. The program offers an MB, BS after successful completion of twelve semesters (six years)(21, 22).

This study was conducted to compare student's perception towards exam validity, reliability, and difficulty.

\section{Materials and Methods}

\section{Study design}

The study is a cross-sectional study. It was conducted at college of medicine, during the period from January to April 2019.

\section{Materials}


The study used a questionnaire to evaluate student's perception towards the exam items and standard item analysis of the exam.

The questionnaire was developed to gain a deep understanding of students' perceptions towards the exam generally and exam items individually. It was developed by the authors and consultation of medical educationalist and satiation and consisted of two parts. Part one investigates the levels of items difficulty (easy, moderate, and difficult) and whether the specific learning outcome (SLO) from which the items were constructed, were covered or not. The second part encompasses the number of items, their mode of covering the course contents and the ability of exam to assess students. The questionnaire was tested through a pilot study. Data generated from the pilot study were not included in the study.

The exam used in this study was the exam of principles of human diseases course. It conducted in semester two-second year $(n=45)$. The course is integrated and multi-disciplinary. The course exam was developed by the course committee using course blueprint and then approved by the assessment committee. It was formed of MCQs type A. The number of exam items $(n=80)$ was adjusted according to the course blueprint and the tested domains (23). Each item is composed of stem and four options, three distractors, and a single best answer. The correct answer is awarded one mark and no marks for blank or wrong selection. 
The exam was marked (DataLink 1200 - Apperson) and double checked. Standard item analysis was obtained and processed for the study.

\section{Participants}

All students registered for the course of principles of human diseases (2018-2019) were included in the study. Exclusion criteria included students who refused to participate in the study or do not fill the questionnaire. Students filled the questionnaire immediately after completing the exam without identification.

\section{Ethical consideration}

The study was approved by research and ethics committee college of medicine. All students accepted to participate in the study filled a written consent.

\section{Statistical analyses}

The data obtained from both of the questionnaires and the standard item analyze analyzed by using SPSS V20 (Armonk, NY: IBM Corp, USA). Descriptive statistics and Pearson correlation coefficient were applied to measure the significance of difference and correlation among different variables. Level of significance was fixed at $95 \%$, and any $P<0.05$ was considered to be significant.

\section{Results}

\section{Student's perceptions}

The response rate was $88.9 \%$ (40/45). The average students' perceptions of exam items were easy (70.4\%), moderate difficulty (18.5\%) and difficult (11.1\%). All 
most all of the students $(92.3 \%)$ reported that the exam items were covered as an objective during the course. For $57 \%$ of the students, the exam items cover the entire course content. $50 \%$ of the students reported that exam items were not concentrated on certain topic, while, $43 \%$ reported that exam items were concentrated, where $7 \%$ of the students were not sure. For $70 \%$ of the students, the number of test item was adequate to assess them. On the other hand, $43 \%$ of the students considered the test, in general, is adequate to evaluated students and $50 \%$ reported not adequate and the remaining (7\%) were not sure (Figure 1).

The correlation between average student perceptions of items difficulty the difficulty index of exam items were significant. A moderate positive correlation was reported between easy perception and DIF ( $\mathrm{r}=0.7033, \mathrm{p}=.00001)$, which means there is a tendency for high DIF go with high easy perception (and vice versa). Moderate negative correlation reported between moderate $(r=-0.2969, p=.008082)$ and difficult $(\mathrm{r}=-0.6094, \mathrm{p}=.00001)$ student perceptions and DIF (Graph 1).

A significant moderate positive correlation $(\mathrm{r}=.615, \mathrm{p}=.00001)$ was reported between DIF and items from covered SLOs (Graph 2).

\section{Item analysis:}

The total number of the analyzed items was 80 . The average score of the class was $55.5(69.38 \%)$. Class median was 56.0 (70.0\%). KR-20 was 0.906. Students pass rate in the exam was $32.5 \%$ (Pass mark=60). The average DIF of the exam was 
$69.4( \pm 21.86)$. Items were classified according to their difficulty in difficult, moderate (acceptable) and easy (Table 1).

\section{Discussion}

About $92.3 \%$ of the students reported that exam items were from course SLOs. Half of the students reported that the exam covers the course contents. Furthermore, $70 \%$ of the students believe that the exam can assess students.

Approving of exam validity depends on the evidence that can support validity. (5, $6,18)$. The methodology of exam construction (23) expert staff member who involved in the course teaching support the exam validity. Student perceptions in regards to the exam in general, support that the exam measures what is intended to measure and reflect the educational contents. These findings are by previous work of Carmines and Zeller $(18,24)$

KR-20 of the exam was 0.906 . Classification of exam items shows that most of the items were within the acceptable range of difficulty (62.5\%), and only $37.5 \%$ of items were not. It has been reported that the presence of too many easy or difficult items can affect both exam validity and reliability $(5,7)$. According to some authors $(5,12,17,20,25)$ values of KR-20 such as 0.8 or above is ideal and demonstrate excellent reliability of exam and the target goal in clinical practice.

The average DIF of exam according to the standard item analysis was 69.4. The average student's perception of exam difficulty is easy $(70.5 \%)$ and has a 
significant positive correlation $(\mathrm{p}=0.001)$ with DIF. The average exam difficulty is considered as good and acceptable according to College assessment policy and literature $(16,17,19)$. In any exam or test, the average difficulty of items should be adjusted according to the required competencies and students level, and these two points are the areas of concerns for item constructors or assessment composers (5). The current findings of student's perception towards exam difficulty suggested that they underestimated the exam difficulty. Students commonly underestimate their performance rather than the exam difficulty $(5,26,27)$. Van de Watering reported that student's perception toward exam difficulty is differing according to the student performance in the exam(5). Students with higher scores underestimate their performance.

Meanwhile, those with lower scores have more accurate estimations. According to the exam result, the upper students represent $72.5 \%$. However, the class mean and average are relatively similar (55.5 and 56.0, respectively). The result suggested a good student's performance. These findings support the work of Van de Watering(5).

The limitation of the study includes the fewer number of students and application on one course. The strength of the study, the test is considered valid and reliable through several pieces of evidence.

\section{Conclusion}


Student perceptions can support exam validity and reliability. Students can estimate test difficulty, although they were reported to underestimate their performance.

\section{Acknowledgment:}

The author acknowledges the students who participated in the study. Great appreciation was to Dr. Elwathiq Khalid, Dr. K. Salih, Dr. E. Miskeen, Dr. A.MS. Eleragi, Dr. I. Jack, Prof. Masoud Ishag (College of Medicine, University of Bisha) and the appreciation extend to Dr. M. Elhassan (College of Medicine, Qassim University, Saudi Arabia) and my colleagues. Great thanks to Mr. MK. Abid (College of Medicine, King Khalid University, Abha, Saudi Arabia) for the statistical analysis and helpful comments. Special thanks and appreciation to College Dean and Administration of the College of Medicine, University of Bisha (Bisha, Saudi Arabia) for help and allowing the use of facilities.

\section{References}

1. Aleamoni LM. Student rating myths versus research facts from 1924 to 1998. Journal of personnel evaluation in education. 1999;13:153-66. 
2. Zhao J, Gallant DJ. Student evaluation of instruction in higher education: Exploring issues of validity and reliability. Assessment \& Evaluation in Higher Education. 2012;37:227-35.

3. Marsh HW. Students' evaluations of university teaching: Dimensionality, reliability, validity, potential baises, and utility. Journal of educational psychology. 1984;76:707-12.

4. American Educational Research Association, the American Psychological Association, National Council on Measurement in Education. Standards for educational and psychological testing. Washington: American Educational Research Association; 2014:11-26.

5. van de Watering G. Teachers' and students' perceptions of assessments: A review and a study into the ability and accuracy of estimating the difficulty levels of assessment items. Educational Research Review. 2006;2:133-47.

6. Bonner SM. Validity in Classroom Assessment: Purposes Properties, and Principles. In: McMillan JH, editor. SAGE handbook of research on classroom assessment. California: SAGE Publications; 2012:87-107.

7. Linn RL. Educational Measurement. Michigan: Oryx Press; 1993:60-70.

8. Considine J, Botti M, Thomas S. Design, format, validity and reliability of multiple choice questions for use in nursing research and education. Collegian. 2005;12:19-24. 
9. Abdulghani HM, Ahmad F, Ponnamperuma GG, Khalil MS, Aldrees A. The relationship between non-functioning distractors and item difficulty of multiple choice questions: a descriptive analysis. Journal of Health Specialties. 2014;2:14853.

10. Lai H, Gierl MJ, Touchie C, Pugh D, Boulais A-P, De Champlain A. Using automatic item generation to improve the quality of MCQ distractors. Teaching and learning in medicine. 2016;28:166-73.

11. Biswas SS, Jain V, Agrawal V, Bindra M. Small group learning: effect on item analysis and accuracy of self-assessment of medical students. Education for health. 2015;28:16-21.

12. Mahjabeen W, Alam S, Hassan U, Zafar T, Butt R, Konain S, et al. Difficulty Index, Discrimination Index and Distractor Efficiency in Multiple Choice Questions. Annals of PIMS. 2017;13:310-5.

13. Shete AN, Kausar A, Lakhkar K, Khan S. Item analysis: An evaluation of multiple choice questions in Physiology examination. Journal of Contemporary Medical Education. 2015;3:106-9.

14. Al-Osail AM, Al-Sheikh MH, Al-Osail EM, Al-Ghamdi MA, Al-Hawas AM, Al-Bahussain AS, et al. Is Cronbach's alpha sufficient for assessing the reliability of the OSCE for an internal medicine course? BMC research notes. 2015;8:582. 
15. Peterson RA, Kim Y. On the relationship between coefficient alpha and composite reliability. Journal of Applied Psychology. 2013;98:194-9.

16. Kehoe J. Basic item analysis for multiple-choice tests. Practical assessment, research \& evaluation. 1995;4:20-4.

17. Cortina JM. What is coefficient alpha? An examination of theory and applications. Journal of applied psychology. 1993;78:98-103.

18. Pande SS, Pande SR, Parate VR, Nikam AP, Agrekar SH. Correlation between difficulty \& discrimination indices of MCQs in formative exam in Physiology. 2013.

19. Bland JM, Altman DG. Statistics notes: Cronbach's alpha. Bmj. 1997;314:572-3.

20. Carmines EG, Zeller RA. Reliability and validity assessment. California: Sage publications; 1979:17-29.

21. Mitra N, Nagaraja H, Ponnudurai G, Judson J. The levels of difficulty and discrimination indices in type a multiple choice questions of pre-clinical semester 1, multidisciplinary summative tests. IeJSME. 2009;3:2-7.

22. Streiner DL. Starting at the beginning: an introduction to coefficient alpha and internal consistency. Journal of personality assessment. 2003;80:99-103. 
23. Dent JA. Using the SPICES model to develop innovative teaching opportunities in ambulatory care venues. Korean journal of medical education. 2014;26:3-7.

24. Ibrahim ME, Al-Shahrani AM. Implementing of a problem-based learning strategy in a Saudi medical school: requisites and challenges. International journal of medical education. 2018;9:83-8.

25. Ibrahim ME, Al-Shahrani AM, Abdalla ME, Abubaker IM, Mohamed ME. The effectiveness of problem-based learning in Acquisition of Knowledge, soft skills during basic and preclinical sciences: medical Students' points of view. Acta Informatica Medica. 2018;26:119-24.

26. Abdellatif H, Al-Shahrani AM. Effect of blueprinting methods on test difficulty, discrimination, and reliability indices: cross-sectional study in an integrated learning program. Advances in medical education and practice. 2019;10:23-8.

27. Sullivan GM. A primer on the validity of assessment instruments. J Grad Med Educ. 2011;3:119-120.

28. Brown S, Knight P. Assessing learners in higher education. Oxon; Taylor \& Francis Group: 2012:9-49.

29. Rezigalla AA. Angoff's method: The impact of raters' selection. Saudi Journal of Medicine and Medical Sciences. 2015;3:220-6. 
medRxiv preprint doi: https://doi.org/10.1101/19002535; this version posted August 9, 2019. The copyright holder for this preprint (which was not certified by peer review) is the author/funder, who has granted medRxiv a license to display the preprint in perpetuity.

It is made available under a CC-BY-NC-ND 4.0 International license .

30. Dochy FJRC. Assessment of prior knowledge as a determinant for future

learning: The use of prior knowledge state tests and knowledge profiles. Heerlen

Centre for Educational Technology and Innovation, Open University; 1992:70-9. 
medRxiv preprint doi: https://doi.org/10.1101/19002535; this version posted August 9, 2019. The copyright holder for this preprint (which was not certified by peer review) is the author/funder, who has granted medRxiv a license to display the preprint in perpetuity.

It is made available under a CC-BY-NC-ND 4.0 International license .

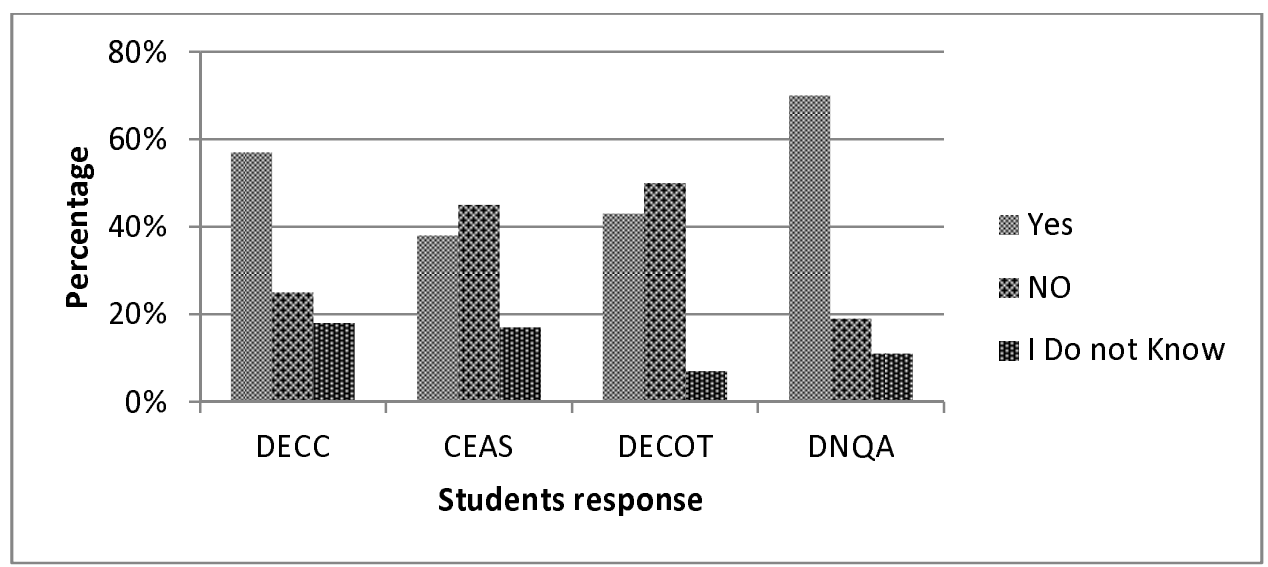

Figure (1): Students perceptions towards exam. DECC, Does the exam cover the entire course; CEAS, Can the exam assess students; DECOT, Does the exam concentrate on certain topics; DNQA, Does the number of question is adequate to assess students. 
medRxiv preprint doi: https://doi.org/10.1101/19002535; this version posted August 9, 2019. The copyright holder for this preprint (which was not certified by peer review) is the author/funder, who has granted medRxiv a license to display the preprint in perpetuity.

It is made available under a CC-BY-NC-ND 4.0 International license .

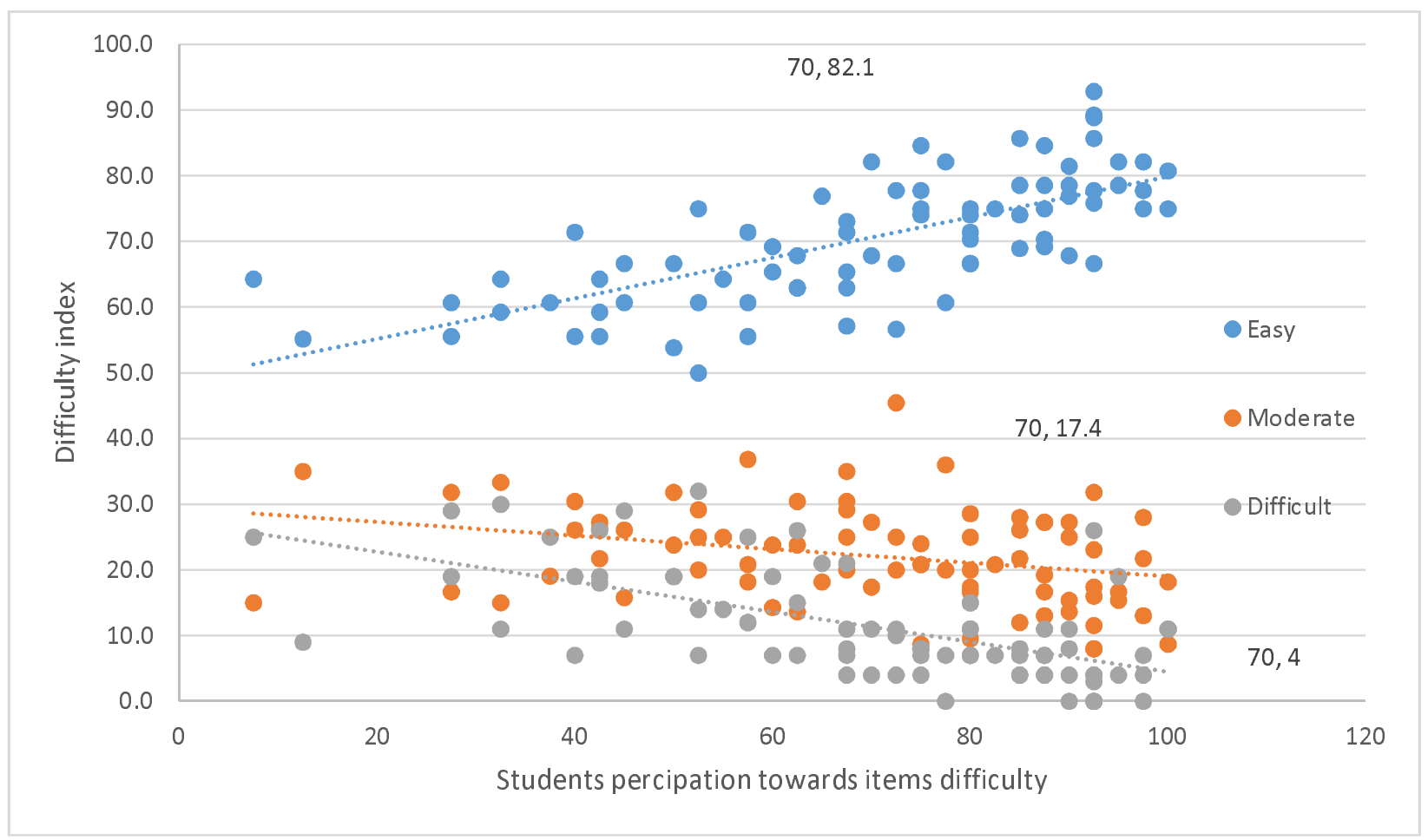

Graph 1: Correlation of student's perceptions towards item difficulty and the standard difficulty index of items. 
medRxiv preprint doi: https://doi.org/10.1101/19002535; this version posted August 9, 2019. The copyright holder for this preprint (which was

It is made available under a CC-BY-NC-ND 4.0 International license .

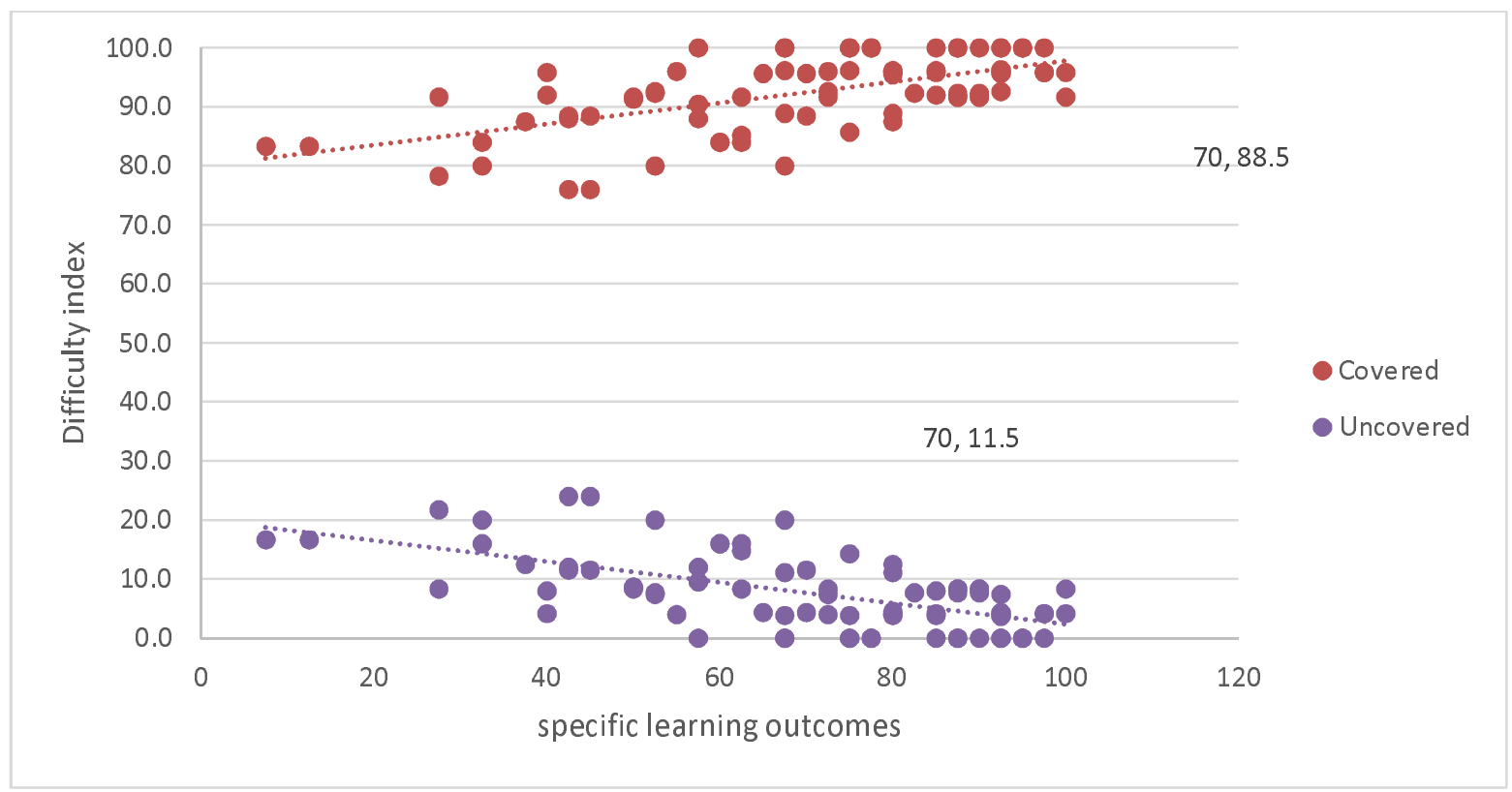

Graph 2: The Correlation between difficulty index of items and the specific learning outcome. 
medRxiv preprint doi: https://doi.org/10.1101/19002535; this version posted August 9, 2019. The copyright holder for this preprint (which was not certified by peer review) is the author/funder, who has granted medRxiv a license to display the preprint in perpetuity.

It is made available under a CC-BY-NC-ND 4.0 International license .

Table (1): Classification of exam items according to difficulty index.

\begin{tabular}{|l|l|l|l|l|l|l|}
\hline \multirow{3}{*}{ Parameters } & \multicolumn{2}{|l|}{ UBCOM } & \multicolumn{2}{l|}{$(16)$} & $(19)$ \\
\cline { 2 - 7 } & Interpretation & $\%$ & Interpretation & $\%$ & Interpretation & $\%$ \\
\hline \multirow{3}{*}{ DI } & Easy $(<80)$ & 35 & Easy $(>70)$ & 52.5 & Easy $(>80)$ & 35 \\
\cline { 2 - 7 } & Moderate (25-80) & 62.5 & Acceptable (30-70) & 42.5 & Acceptable (30-80) & 60 \\
\cline { 2 - 7 } & Difficult (0-25) & 2.5 & Difficult (<30) & 5 & Difficult (30<) & 5 \\
\hline
\end{tabular}

\section{DI, Difficulty index.}

